\title{
A Kiss for Three Decades: Comparative Researches on Film Language and Tourism Destination Image between two versions of "Romance on Lushan Mountain"
}

\author{
Danling Luo ${ }^{1,2}$, Haowen $\mathrm{Lin}^{3}$, Zhou $\mathrm{Li}^{2} \&$ Yong $\mathrm{Liu}^{1,2}$ \\ 1 School of Management, Jinan University, Guangzhou, China \\ 2 Shenzhen Tourism College, Jinan University, Shenzhen, China \\ 3 Peking University, Haidian District, Beijing \\ Correspondence: Zhou Li, Shenzhen Tourism College, Jinan University, Nanshan District, Shenzhen, 518000, \\ China. Tel: 86-1-392-740-4224. E-mail: 258302752@qq.com
}

Received: August 5, 2013 Accepted: September 16, 2014 Online Published: September 29, 2014

doi:10.5539/ass.v10n19p240 URL: http://dx.doi.org/10.5539/ass.v10n19p240

\begin{abstract}
Expression of visual image via brochures, billboards, TV commercials, newspapers, movies, etc. has been widely applied into promotion of tourism products, urban landscape, natural scenery, tourist destinations, and even changed communication way between tourist information and potential visitors. Many scholars have made substantial and valuable researches on still images, however, moving images are very critical to tourism industry, and should be further researched and attended academically.

It has been verified and proven from researches of some scholars that movie makes important influence on tourism experience, travel motivations, destination marketing and other aspects as one of dynamic image expressions; however, under different cultural backgrounds, a movie conveys different connotations, but orientalism reason is rarely considered by scholars. In addition, many scholars only consider movie as an influential factor, and few pay attentions to the language and meaning or cultural connotation conveyed by a movie itself. Therefore, the paper interprets two versions of the Chinese movie "Romance on Lushan Mountain", which production time was separated by three decades, and competitively studies difference in expression and image establishment of the tourist destination Lushan between two versions.

Visual analysis method is applied to textual interpretation of the movie; it is shown from results the visual image of Lushan, the tourist destination in the movie, is both adhered and also carried forward through such two versions. The first version focuses on local natural beauty, and integrates values of love and historical background into the tourist attractions closely, thus making wide and lasting impact on tourists; the second version highlights to establish an emotional connection with the previous version, and enriches other images of the destination in addition to natural scenery, where modern city life and truelove are combined in the image promotion of tourist destination; however, from the point of expression method, the second version is excessively commercialized, and criticized as a formulaic and conventional story, which influence is poorer than the previous versions.
\end{abstract}

Keywords: film tourism, film language, tourism destination, romance on Lushan Moutain

\section{Introduction}

Movie tourism, a new term combining two industries, has appeared and been highly attended in European and American scholars and practitioners over the second half of the 20th century. As popularization of Korean and Japanese dramas in Asia, movie tourism is under blowout development in Asian countries. Since the 1990s, shooting location tourism has appeared in China; movie theme park, movie travel routes and other travel-related products were attended and promoted in academia within a certain time, but they has not yet been integrated and established as a system.

Movie, as a communication media, is capable of continuously promoting advertising effects of a tourist destination. A movie may help visitors experience charm of tourist destination in theater and even at home, thus to shorten time and space, mobilize visitors to image; it provides much information and stories where tourists are 
able to experience and further realize during travel to shooting location. For example, New Zealand is successfully promoted and advertised by using the movie "Lord of the Rings"; the British Tourist Authority launches the promotion project "Movie in London" where many famous movies are included, such as Harry Potter, 007 and other works related to tourism products; New York is positioned as an attractive and charming city and targets at female tourists by the movie "Sex and the City".

It is undoubted Western movies become the focus of academic research, but some conclusions are not applicable into Chinese market, due to different cultures and different internal relations \& external expression; As for Chinese movies, it is necessary to consider local culture, times, consumers and other background factors. The paper targets at two versions of "Romance on Lushan Mountain", which represent love-themed sightseeing districts respectively under the different background; the first version of "Romance on Lushan Mountain"(1980) is the first romance movie after "Chinese Cultural Revolution (CCR)", where the kiss image appeared in the screen of "Red-China" for the first time, and such a movie evoked Chinese young to learn English, dress fashionable cloths, thus causing a sensation in the 1980 s, not only carrying the imagination and longing to the beautiful scenery of Lushan by the generation experiencing CCR, and also symbolizing liberation and innovation of social thought in Chinese cultural field.

The second version named as "Romance on Lushan Mountain 2010" was shot and produced after 30 years when China is developing politically, economically and culturally, and the new movie is considered as a continuation of previous "Romance on Lushan Mountain" (1980); the modern romance story is integrated in still beautiful and gorgeous scenery in Lushan, and also expresses a change in Lushan tourist destination, travel motivation and values of love under different backgrounds. Therefore, under the same scenery in Lushan, two versions highlight different values of love, establish emotion and visual image to Lushan under different ages, both two are worth of comparatively research. In this paper, visual analysis method is applied to interpret two movies, and compare expression way of specific circumstances, location, roles and other elements between two movies, thus to highlight differences in promotion of Lushan tourist destination between the two movies under different background.

\section{Literature Review}

Increasingly enhanced image expression has changed mode of communication between travel information and potential visitors. A series of visual information constitute an important part of tourists' memory, enrich tourists' experience, and become the main purpose of travel in some cases. This is the first time that still images (such as photographs, postcards, brochures, pictures) are applied as visual data in the tourism research by Chalfen(1979) where he describes the important relationship between visitors types and shooting behavior patterns. Then, Uzzell (1984) makes visual image analysis on brochures of vacation market targeting at customers at 18-35 year olds, and further summarizes the impact of symbolic structures.

By analyzing 1500 postcards, Edwards (1996) proposes "analysis on how tourists express is critical to understanding tourism phenomenon". Pritchard (2001) conducts a gender visual representation analysis on guidebook of British Travel Agents, and proposes measurement scale "sexism in tourist expression". Markwick (2001) studies applicable regulating range for making and production of commercial images, such a regulation is impacted by the needs and expectations of tourists, because the analysis material comes from local production, his study is involved in a new field research on self-expression for tourism market.

Castelltort \& Mader (2010) select seven Swiss news media to analyze German reports from positive, neutral and negative views, and assesses communication image of Spanish tourist destinations in monetary value. By comparing the perceived image and projected image of Peru, Stepchenkova \& Fangzi Zhan (2013) concludes 20 attributes of destination through content analysis, and compares characteristics of different regions in Peru by application of geo-map.

It is shown from the research methods that most researchers adopted content analysis method and symbolic analysis method; then some scholars applied rhetoric, narrative, or pragmatic analysis method or comprehensive analysis method combining different methods (Bai,2008; Hunter, 2008; Hunter, 2013), or visitor employed photography, conducted interviews, questionnaires, adopted structural equation modeling method, corresponding analysis and other methods, thus improving the comprehensiveness and reliability of their study (Markwell, 1997; Xiao, 2009; Liu, 2013). Their study objectives include: to identify destination tourist attraction and tourist destination image (Uzzell, 1984; Cohen, 1989; Selwyn, 1993; Echtner, 2002); to explore impact of different media information on the tourism destinations and related marketing effectiveness (Lin \& Huang, 2006; Zhang, 2010); to analyze tourism motivation and decision-making behavior of potential tourists (Markwick, 2001; Stepchenkova, 2006; Liu \& Bao, 2006; Lepp, 2011); to focus on psychological characteristics and attitudes of 
photography tourists; to research the theme, resources and space of regional tourism, and to promote sound development of regional tourism (Baloglu, 2001; Wang, 2012).

Compared to static visual material, less dynamic images are studied and attended, which is roughly divided into two areas. One is represented by cultural scientists, and targets at environmental concerns, focus on cultural impact on audiences, residents and tourists (Tzanelli, 2003; Winler, 2003); the other centers on influence of movie on tourists' travel motivation and travel experience, as well as number of tourists, economic activities, and marketing activities in shooting location. For example, by analyzing the movie "Notting Hill", Busby \& Klug (2001) think the movie establishes a pre-traveling image and makes important contribution to promoting and positioning London as a fashion sense; they attempt to explore relations between the motivations and expectations of tourists by questionnaire survey method. Gundle (2002) analyzes how Hollywood culture affects the movie "La Dolce Vita", in turn, the movie establishes an attractive image for Rome, and positions as a cosmopolitan city and fashion city, thus promotes the prosperity of exports and tourism. Connell (2005) reports on a survey of tourism business operators on Mull and provides evidence of the nature and scope of the impact of television-induced tourism on tourism business performance and activity, indicating that the effects were concentrated spatially and temporally. Connell (2009) then explores the interface between the screen tourist and the destination in this case, and identifies that the lower the influence of Balamory for the visit, the higher the level of adult satisfaction, and that a return visit was more likely if visitors were satisfied with their trip, especially if Balamory was not the only reason for the visit. Kim (2012) explores audience involvement or engagement with a serialized TV drama how to affect their actual on-site film tourism experiences at its former film locations.

Thus it can be seen that the study on motion picture have created a lot of achievements in tourism experience, tourism motivation, tourism marketing and other areas. But among most of the literatures, movie is considered as an influencing factor, few scholars take movie as text (language), and further analyze deeper influence from various elements of movie including actors, directors, and spectators, on such a movie and related tourist destination; also rare scholars analyze different establishment method of tourism destinations from view of era backgrounds.

In addition to analyze specific scenario, location, roles, and other elements, it is required to understand how these elements are expressed and conveyed to audiences, thus to interpret ad understand a movie better. Escher \& Zimmerman (2001) point out that the language of movie aims to integrate strong relation with landscape destination, location, and emotion into a movie closely. Riley \& Mackworth (1998) think that the strong relation also includes symbolic meanings in the film and destination. Beeton (2005) believe that one of film languages is to place ourselves into movie's scenario, vision, sound, and emotion. Kim (2012) believes that film language is a description to tourists that contributes to their expectation, and highlights the fantasy, nostalgia, memory and emotion in a film.

Hence, films could be seen as the composition of film language and directors or editors make use of film language to engage an audience and its emotions (Hao \& Ryan, 2013).. To some extent, therefore, film language may induce or reinforce a viewer's tourism imaginaries, which often become the symbolic objects (Salazar, 2012).

\section{Methodology}

Boraas (2000) and Brown (2001) think each element of image is a conscious choice by director, and each group of images have an important positive impact on meaning of the movie, such these elements include music, background, camera angles, costume, actors, etc. Monaco (2000) presents a dynamic image interpretation method. From point of space and time, Rose (2001) concludes a movie structure analysis model to generalize. This paper summarizes the above four scholars' views on film language analysis, and summarizes them in the following analytical framework (Table 1).

It is noted that this method of analysis is conductive to analyze film language and structure, but the movie results from interaction of subject matter, moviemakers, and audience (Offler, 1999), and it is incapable to supersede conceptual work, deep thinking and complex description (Greertz, 1973); in addition, such a deconstructive analysis is based on objective and universal perspective, and partially ignores the artistic value of a movie. In this regard, the paper applies the method in a critical manner.

Movie analysis is divided into four stages, and aims at concluding Lushan image and emotional establishment expressed via the movie. The first stage is repeated viewing and discussion of the movie, summarizing the scenario structure, artistic expression and key clip. The second stage is to collect background information of two movies, including political, economic, cultural background, as well as directors, actors and other information, 
and also to classify relevant literatures and comments on "Romance on Lushan Mountain" (1980) and "Romance on Lushan Mountain 2010"; the third stage is to analyze the movie by utilizing sorted-out analytical framework and the supplement as described in the second stage, to conclude image establishment and of Lushan tourist destination, as well as sentimental value contained herein. The fourth stage is to compare and summarize two differences in two destination image building.

Table 1. Film language analysis

\begin{tabular}{|c|c|}
\hline Factors & escriptions \\
\hline $\begin{array}{l}\text { Contents } \\
\text { information }\end{array}$ & itle, Director, Production time, Length of a film(minute) \\
\hline Movie type & $\begin{array}{l}\text { Fiction type (theatrical movie, character movie, comedy, action movie, adventure movie, } \\
\text { mystery movie, suspense movie, etc.) } \\
\text { Historical fiction piece (national history drama, historical drama) } \\
\text { Documentary (ethnographic movie, historical movie, current affairs movie, etc.) }\end{array}$ \\
\hline $\begin{array}{l}\text { Literary } \\
\text { analysis }\end{array}$ & $\begin{array}{l}\text { Information conveyed via a movie; point of view conveyed via a movie; "conflict", tense } \\
\text { scenario, and inflection point of story as intentionally designed; the way to resolve the conflict; } \\
\text { story expression method by different roles; impact of these roles in main conflict; }\end{array}$ \\
\hline \multirow[t]{4}{*}{$\begin{array}{l}\text { Aesthetic } \\
\text { analysis }\end{array}$} & $\begin{array}{l}\text { particular ways through which moviemakers establish structure, theme and experience; } \\
\text { elements of background; main roles of light, color and shadow }\end{array}$ \\
\hline & $\begin{array}{l}\text { Shooting distance: ultra long-range perspective, long-range perspective, panoramic, side view, } \\
\text { medium shot, head and shoulders, close-up }\end{array}$ \\
\hline & Shooting focus: depth or simple, sharp or soft \\
\hline & gle, look-up angle, rotation angle \\
\hline \multirow[t]{2}{*}{ Film editing } & $\begin{array}{l}\text { Film length, showing speed, rhythm range. How to parallel image and lens; main implied } \\
\text { meaning expressed via a movie (clear or fuzzy)? Film editing coherence (available in } \\
\text { storytelling)? Theme and emotion of movie determined in the beginning of movie (including } \\
\text { opening subtitles)? }\end{array}$ \\
\hline & mless type, ablation type, circle animation type, and jumpin \\
\hline $\begin{array}{l}\text { Sound } \\
\text { recordings }\end{array}$ & $\begin{array}{l}\text { Movie sound can be divided into three types (background sound, dialogue and soundtrack). } \\
\text { Emotional elements conveyed during dubbing, and main roles of dubbing }\end{array}$ \\
\hline
\end{tabular}

Source: Brown (2001), Boraas (2000), Monaco (2000), Rose (2001)

\section{Analysis on the Film language of "Romance on Lushan Mountain" (1980) and "Romance on Lushan Mountain 2010"}

\subsection{Introduction to the Movies}

"Romance on Lushan Mountain" (1980), telling the romantic story between Zhou Jun, the daughter of a retired Kuomintang general and Geng Hua, the son of a CPC general Geng Feng in Lushan Mountain, is the first love film shot after the Cultural Revolution. After the establishment of diplomat relation between the People's Republic of China and the United States, Zhou Jun, who now lives in America, visits mainland China for sightseeing. In Lushan Mountain, she meets Geng Hua and they fall in love with each other. Geng's father, a CPC officer, is under political investigation by Gang of Four at that time. Due to his frequent contacts with Zhou, Geng is summoned for interrogation, so Zhou returns to the States with regrets. After the fall of Gang of Four, Zhou pays a visit to Lushan Mountain again. While Geng, now a postgraduate student of Tsinghua University, happens to come to Lushan Mountain for academic colloquium. They feel joyful about this reunion and decide to marry each other. However, Geng Hua's father, Geng Feng recognizes that the girl's father was his opponent back in the Civil War. Thus, he hesitates about this marriage. After some struggles, the two seniors, both with the intention of reunification of China, meet on Lushan Mountain and Zhou Jun and Geng Feng finally get married.

"Romance on Lushan Mountain 2010" is a sequel of "Romance on Lushan Mountain" (1980). After 30 years, middle-aged Zhou Jun has become a successful businesswoman, charging of a large group company. Her daughter, Geng Fenger, who returns to China after graduation, falls in love with Wei Ning, a business elite. Soon she meets with a freelance photographer Ma Jiang in a flight trip and also has feels for him. Geng Fenger, ever 
since trapped in this intricate love entanglement with two leading actors, eventually finds her own true love in the conflict with her mother, in the check of reality and upon returning to Lushan Mountain.

\subsection{Analysis of "Romance on Lushan Mountain" (1980) and "Romance on Lushan Mountain 2010"}

Table 2 analyzes the fundamental structure of "Romance on Lushan Mountain" (1980). Aesthetic analysis, film editing and sound recording analysis will be discussed with specific scenes of the film.

Table 2. The fundamental structure of "Romance on Lushan Mountain" (1980)

\begin{tabular}{ll}
\hline factors & description \\
\hline Contents & Title: "Romance on Lushan Mountain" (1980) \\
information & Director: Huang Zumo \\
& Production time:1980 \\
Length of a film: 01:21:52minutes & a fictional love story \\
film type & 1) Zhou and Geng fall in love with each other in Lushan Mountain; experiencing ups and \\
literary & downs, they get married at last. \\
analysis & 2) love at first sight, love with political background, love in beautiful scenery \\
& 3) There are three ups and two downs in the structure. The first up is their love at the first sight; \\
the first down is their separation because of political reasons; the second up is their reunion in \\
Lushan Mountain and engagement following the end of political struggle; the second down is \\
their fathers' hesitation about their marriage due to the past political struggle; the third up is \\
their meeting with each other after their fathers agrees to forget unpleasant history and support \\
their marriage. Every up is related to the beautiful scenery of Lushan Mountain and every down \\
is caused by political background at that time. The turning points of the film are connected with \\
Chinese destiny and the solutions of conflicts are associated with national unification. So to \\
some degree, Lushan Mountain represents "China", expressing patriotism of ordinary Chinese. \\
The film becomes a tool to guide film viewers to form a new national image in the new era at \\
the end of the Culture Revolution and in the beginning of reform and opening up. \\
4) The hero, Geng Hua is a righteous, patriotic and diligent young man. But due to his father is \\
under political investigation and his mother is seriously ill, accompanied by his traditional \\
growth environment, he suffers from depression. So at the same time, he is a conservative, dull \\
and simple boy. The heroine is a girl with overseas education, thus she is open, mischievous, \\
pretty, warm, brave and persistent. Their contrast characteristics imply that the girl's love is like \\
ebullient rose and the boy's love is like remote and shy stars, which reaches climax when the \\
girl kisses the boy actively. While the introduction of their family background suggests that \\
most twists and turns come from the boy's family.
\end{tabular}

(1) Several travels of the leading actors

"Romance on Lushan Mountain" (1980) includes several travels of the two leading actors. Geng Hua's first visit to Lushan Mountain is essentially self-exile to stay away from politics in the Culture Revolution, so he moves from the city, that is, the center of political ideology to picturesque Lushan Mountain. His second visit is an academic and leisure trip after his entrance to graduate school, which represents the rising social position of intellectuals. The visit of Zhou Jun and her parents to Lushan Mountain is a return trip of overseas Chinese back to motherland, which is significant in space, culture and ideology. Zhou and Geng wander in Lushan Mountain for two times, visiting famous scenic spots like Flower path, Fairy Lake, the Pavilion made by Zhu Yuanzhang's order, Dragon's Head Rock, Artificial Lake, Hanpo Pass, Donglin Temple and Bright Spring. Their love story also connects these spots as a line, painting a poetic map of Lushan Mountain. Table 3 shows all scenic spots in the movie.

Narrative feature of "Romance on Lushan Mountain" (1980) is similar with scenic film, thus to integrates narrative movie and non- narrative movie closely, forms a work combing scenery introduction, era background and movie scenario. These elements of scenic film marks the movie as a spatial tour guidebook, highlights an open space, which is entirely different with enclosed stage space of model opera in CCR, and features dramatic changes in social culture from view of depth of field, lens position and color. 
Table 3. Scenic Spots Summary in "Romance on Lushan Mountain" (1980)

\begin{tabular}{|c|c|}
\hline Scenic spot & Features \\
\hline Flower path & $\begin{array}{l}\text { Back to Tang Dynasty, it was praised as "the best place of Lushan Mountain". Bai } \\
\text { Juyi, a famous poet in Tang Dynasty described its beautiful scenery in Dalin } \\
\text { Temple Peach Blossoms. }\end{array}$ \\
\hline Fairy Cave & $\begin{array}{l}\text { Flying rocks can hold visitors and clean springs can make you calm down. Vistors } \\
\text { can also enjoy white clouds and grand river here. }\end{array}$ \\
\hline Hanp & place to watch the sunrise \\
\hline Lulin & $\begin{array}{l}\text { A smooth lake raises in narrow gorges and mountains inverts images in the lake. } \\
\text { Mao Zedong swam several times here. }\end{array}$ \\
\hline $\begin{array}{l}\text { White Deer Cave } \\
\text { Academy }\end{array}$ & Surrounded by waters and mountains, this academy is very quiet and peaceful. \\
\hline wing Pavilion & $\begin{array}{l}\text { The pavilion is built on a steep rock and its roof is like an umbrella, natural and } \\
\text { unrestrained. Due to the broad vision in its north, it is the most ideal spot to view } \\
\text { Yangzi River. }\end{array}$ \\
\hline Bright & $\begin{array}{l}\text { A poem of Pi Rixiu, a famous poet of Tang Dynasty is carved in the tablet. The } \\
\text { spring is extremely clean. }\end{array}$ \\
\hline Donglin Temple & $\begin{array}{l}\text { Donglin Temple is the birthplace of Nichiren, a religion that has profound impact } \\
\text { on Buddhists in some countries. And it is one of the three international } \\
\text { communication dojos in Jiangxi Province. }\end{array}$ \\
\hline $\begin{array}{l}\text { the Pavilion made by Zhu } \\
\text { Yuanzhang's order }\end{array}$ & It was built in the rule of Zhu Yuanzhang, facing the west, and has unique shape. \\
\hline Flow Stone & $\begin{array}{l}\text { It is in the front of White Deer Cave Academy and is the place where Zhu Xi, a } \\
\text { neo-confucian in Song dynasty read books. }\end{array}$ \\
\hline
\end{tabular}

In beginning of movie, audiences are deeply impressed by open space and beautiful scenery of Lushan in sunny days under seamless editing approach, as well as delicate rhythm of music "fly to far-off home"; within two minutes and five seconds, the movie director shows original ecological natural landscape of Lushan by super long-range perspective, long-range perspective and panoramic perspectives, in a far-to-near and high-to-low manner. The word "Geese" in lyric aims to imply by an animal, and proposes that the movie's values of love contain patriotic elements (Figure 1). At 31 minutes 45 seconds, both actor and actress are walking around Lushan, the theme "Song of Love" is inserted and sounded; the same language style mirrors the beauty of Lushan, shows the charm of Lushan full of sunshine and bloomy flowers (Figure 2). In the end, such the same approach is adopted to present magnificent and fantasy landscape of Lushan, and clouds offer audiences unlimited imagination on better future (Figure 3).
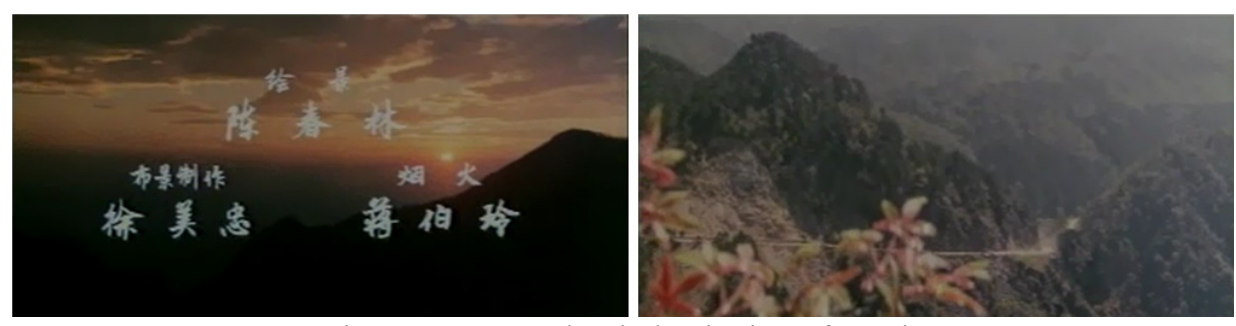

Figure 1. Screenshot in beginning of movie
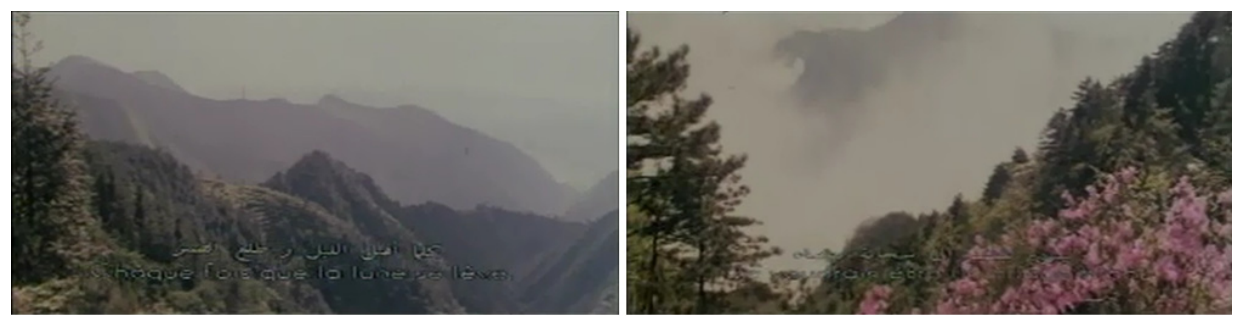

Figure 2. Screenshot in middle of movie 

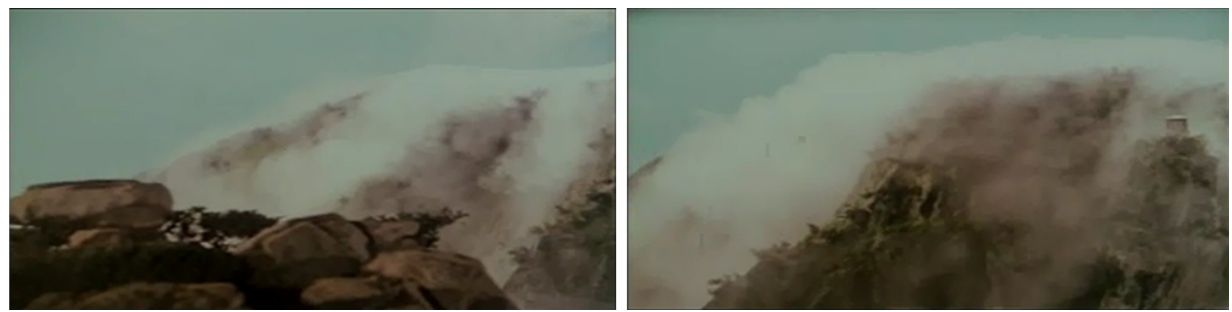

Figure 3. Screenshot in end of movie

The two leading actors meet in Flow Stone, whose full view is shown from the distant to the near in the heroine's angle (downward angle). When the heroine is taking pictures, the hero intrudes without intention to read books. The film describes the concentrated hero as a dull "Confucius" by using four montage shots. However, it is just his dullness that attracts the heroine. At this time, Chinese zither music, a fitting backdrop to the hero's image, also draws audience attention.
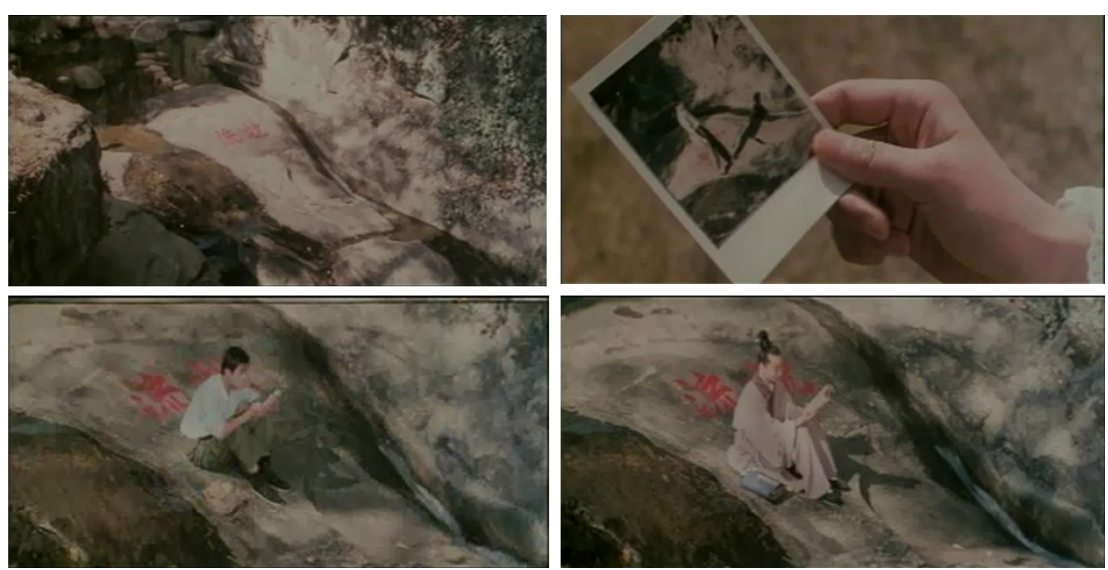

Figure 4. Screenshots of "Flow Spring"

When the heroine visits Lushan Mountain alone, she passes Flow Stone, Flower path, Fairy Cave, Fantastic Rock, all of which are shot from the near to the distant (the focal length changes from short to long). These shots, edited together without break and accompanied with soft music, are presented slowly in the film.
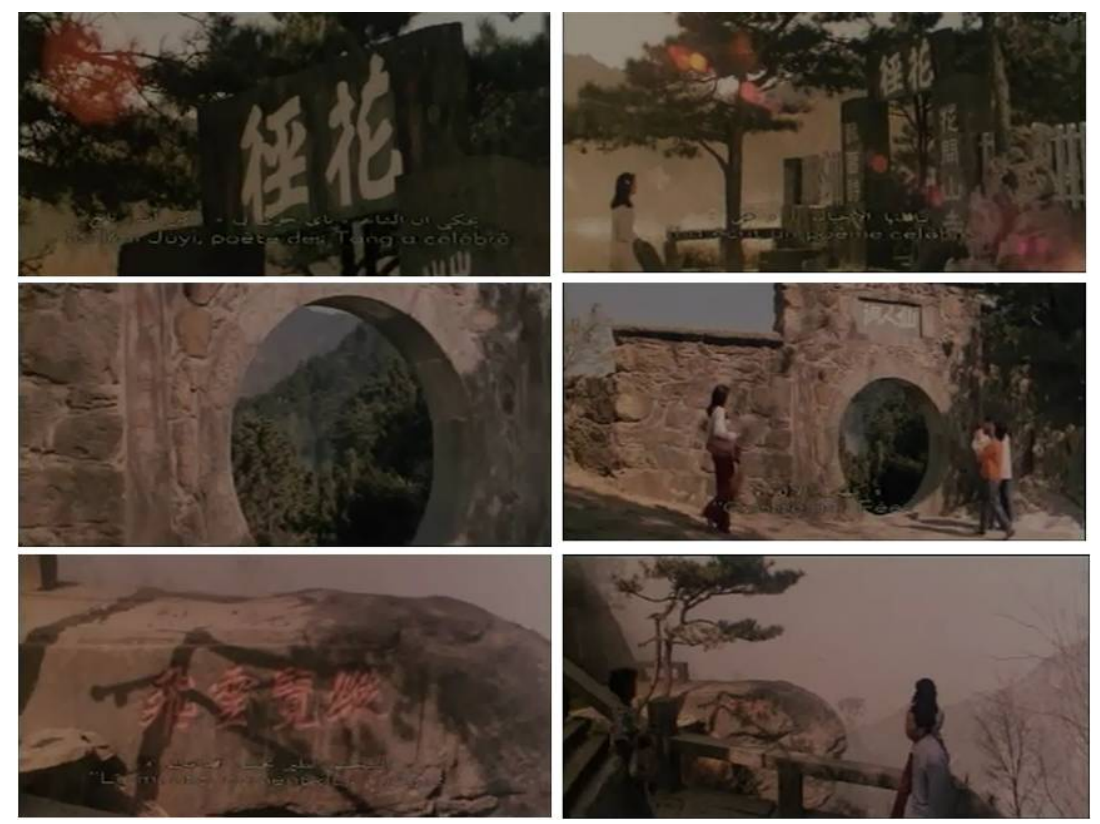

Figure 5. Screenshots of the Heroine's Visit Alone

When the two leading actors visit together, Dragon's Head Rock, Triple-lap Spring and Hanpo Pass are also shown from the distance to the near in the background of the theme song Love Song. Audience can enjoy a visual journey in this process. Meanwhile, their family backgrounds are introduced here. 

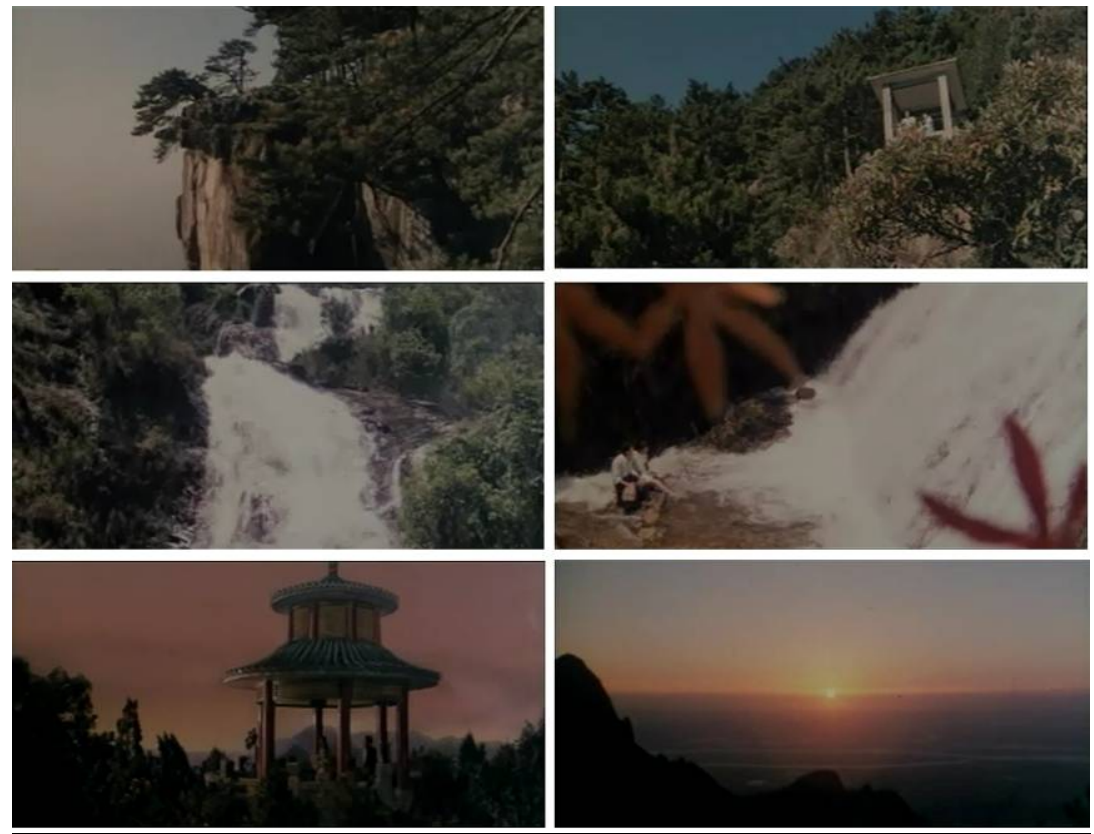

Figure 6. Screenshot of travel of male and female leads in the movie

(2) Travelers' sensory experiences, reproduction and cultural reflection

In the movie, Lushan's landscape information not only provides travelers with sensorily pleased sightseeing spots, and attracts such travelers to further experience and realize personally in actual travel. As introduced by Geng and Zhou's elder generation, Lushan's natural scenery, historical allusions and associated political vicissitudes could be integrated into their travel and experience. Therefore, travel process as shown in the movie is similar with religious pilgrimage: the travelers personally verify Lushan image previously provided by their parents, and form unique personal travel experience and cultural consistence with their parents in the process. At the same time, such the travel is described as a process of knowledge construction and dissemination. For example, Zhou's "guidebook" is the information dictated by his father and hand-drawn map, representing the extension of family culture deposit. Travel map illustrates travelers' perceptual experience, and is considered as a research sample for spatial, historical, intellectual and cultural ideas, due to differences in drawing way and symbols.

In contrast, Zhou operates Polaroid camera to shot visual landscape of Lushan, indicating young women's travel experience and social activities, and playing a more important narrative function in re-establishment of Lushan landscape and relationships, forming a private life expression in contrast to natural landscape containing national or ethnic significance. Thereby, a visual culture system is established and composed of map, photographs, sketches paintings and other visual text forms in the movie, and matched with character dialogue and voiceover for scenery introduction, thus contributing to knowledge-based expression on natural and cultural landscape of Lushan(Figure 7).
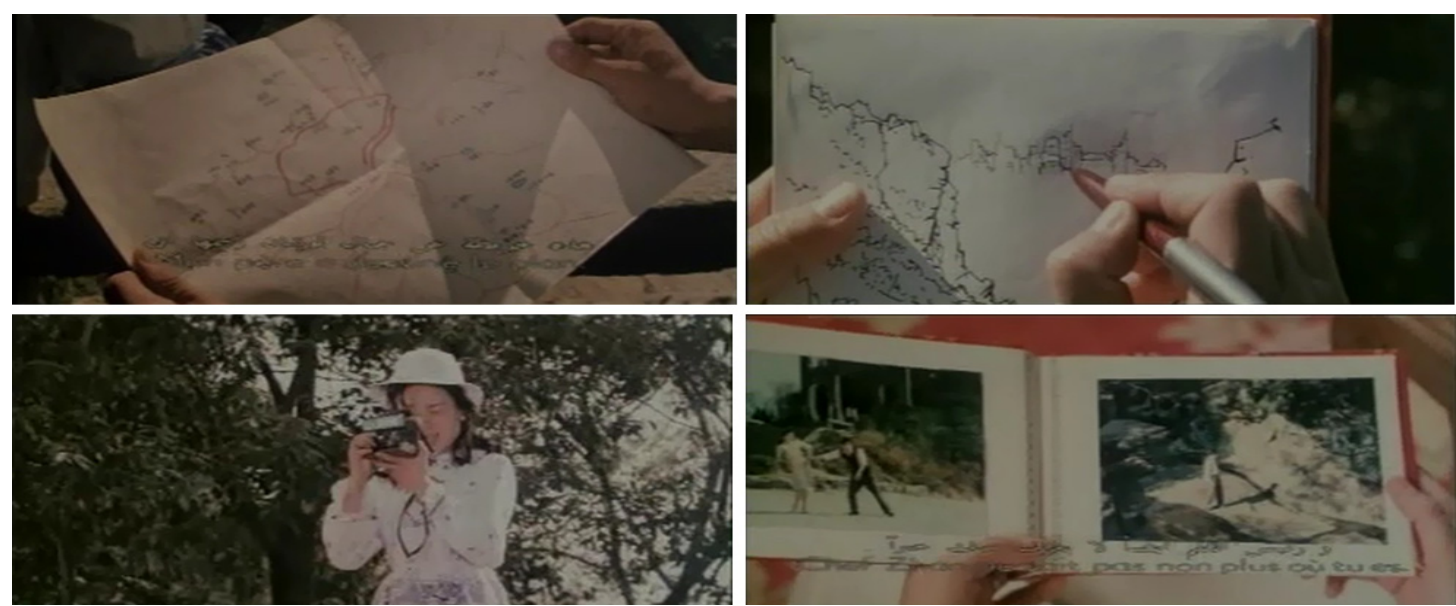

Figure 7. Screenshot of maps, sketch paintings, cameras and photo 
(3) Construction of intellectuals' subjectivity and ideology in 1980s

Narrative features of "Romance on Lushan Mountain" (1980) cater to and satisfy sensory needs and travel desires of moviegoers in Chinese mainland in the early 1980s, also utilize landscape beauty to remedy "Cultural Trauma" caused by CCR. Modern national state may promote "space nationalization" through two approaches: "monumental geographical landscape" and "rewriting history" thereby strengthen the cultural identity nation-wide and ethnic-wide. From the view, the movie presents Lushan in a more knowledgeable manner, thus leads a nationalized expression on the landscape, and further guides audiences to experience ideology as well as historical and cultural tour. There fantasy natural and cultural landscape brings travelers historical and visual spectacle, and also are considered as national cultural spectacle.

This is fully highlighted in two typical scenes in the movie especially, the first scenario is Geng reviews English in woods, Zhou, as a returnee, correct his pronunciation with more standard American English, as they read "I love my motherland, I love the morning of my motherland."; the second scene is they shout out the same two sentences in Hanpo Pass when both lovers are intoxicated by surrounding landscape.

The another point is reflected in the scenarios of heroine's father in the United States where the "geese" and "China-brand cigarettes" are used for implying patriotism of oversea Chinese(Figure 8). In addition, Chinese fiddle and zither are commonly used for expressing sentiment of the missing; however, an American popular music is played by acoustic guitar for the background when both Zhou and his father stay in the United States, such a fair-sounding music expresses their homesickness, also matches with the characters' cultural background while living in a foreign country, and fully demonstrates such blazing and delicate emotions.
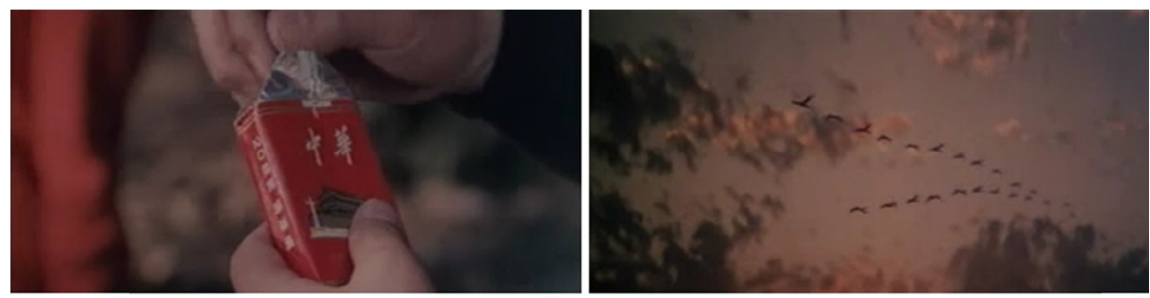

Figure 8. Chin-brand cigarettes and geese scenes

(4) Analysis on inflection point of movie scenario

In "Romance on Lushan Mountain"(1980), a lot of scenes are integrated with external natural environment and other elements to express the scenario inflection. In "River-viewing Pavilion" attraction, Zhou and Geng meet again in time of taking shelter from rain, and fall in love each other. After the scenario, both two are further familiar with each other and go out for travel together. This scenario expresses inflection of scenario structure by utilizing weather and light change. Another set of scenarios appear in Zhou's house, Zhou is greatly happy and pleased when Geng comes for her, as well as she makes a cruel decision to refuse Geng in order to protect Geng. Both images are expressed with the same bunch of flowers; the previous is based on repeated conversion between close-ups to close-range perspective; the latter is highlighted with thunderstorm night background (Figure 9). Another scenario appears in last inflection point of the story where a mirror is broken when Geng and Zhou are unable to continue their relationship due to the reason from their last generation, in a repeated conversion approach between fuzzy and clear perspective, thus to imply the heroine's sadness (Figure 10).
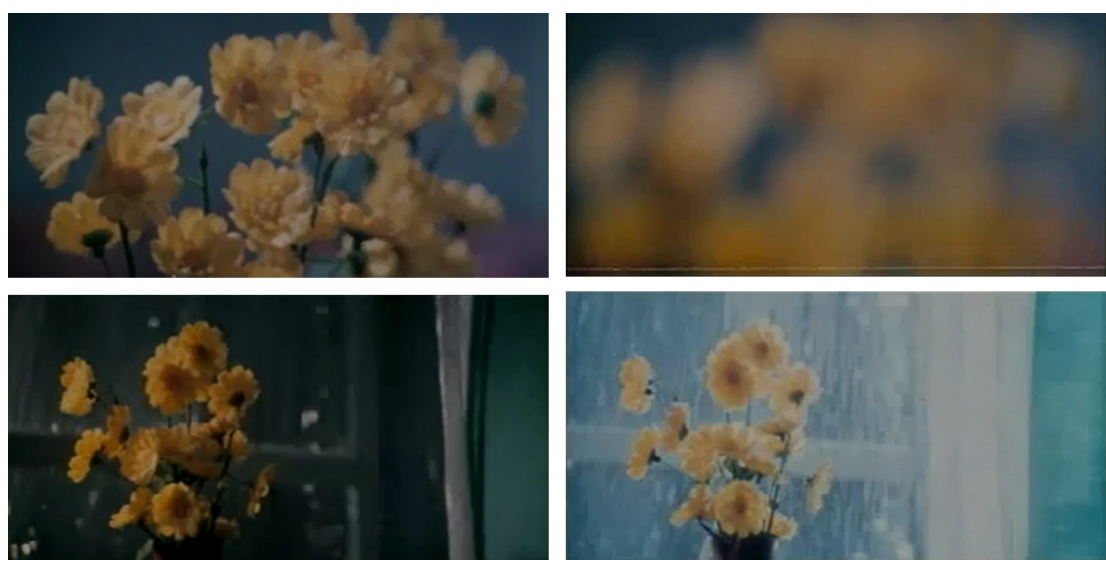

Figure 9. Two flowers scenes 

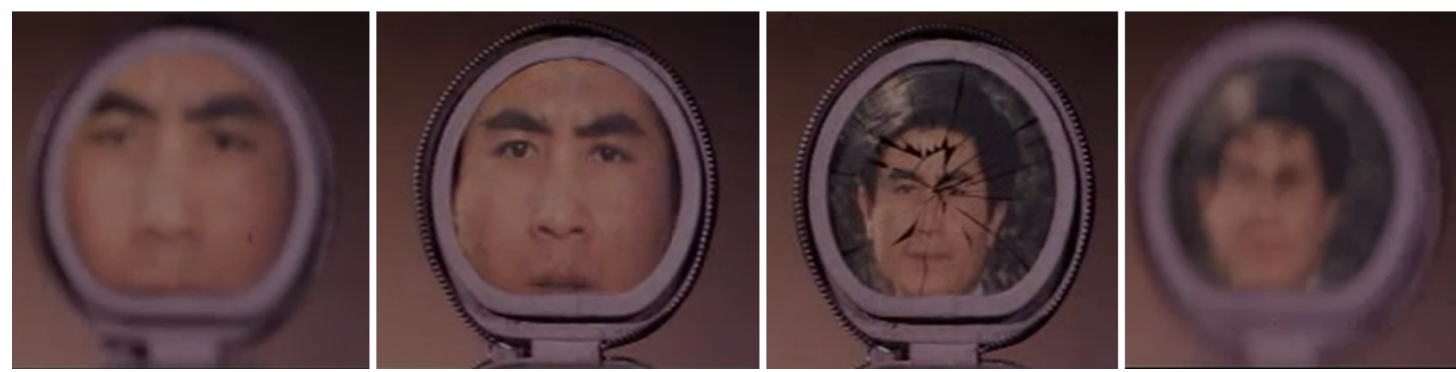

Figure 10. Mirror-implying inflection scenario

(5) Analysis on influential scenario of the movie

A few typical scenes in "Romance on Lushan Mountain" (1980) have still affected image construction of tourist destinations and related activities till now. Thereinto, one is Flow Stone attraction where hero and heroine meet as previously described; the other is the place where both hero and heroine watch the sunrise in Lushan Mountain; as well as Bright Spring where they drink spring, and Hanpo Pass where they take photo (Figure 11). These scenarios establish imagination and expectation of audiences on Lushan successfully, and thereby they are able to personally experience such the scenarios in actual tourism (Figure 12); to this end, people said, and one who fails to watch sunrise in Lushan is not a real visitor to Lushan. This is one of influence from the movie on the tourism destination marketing.
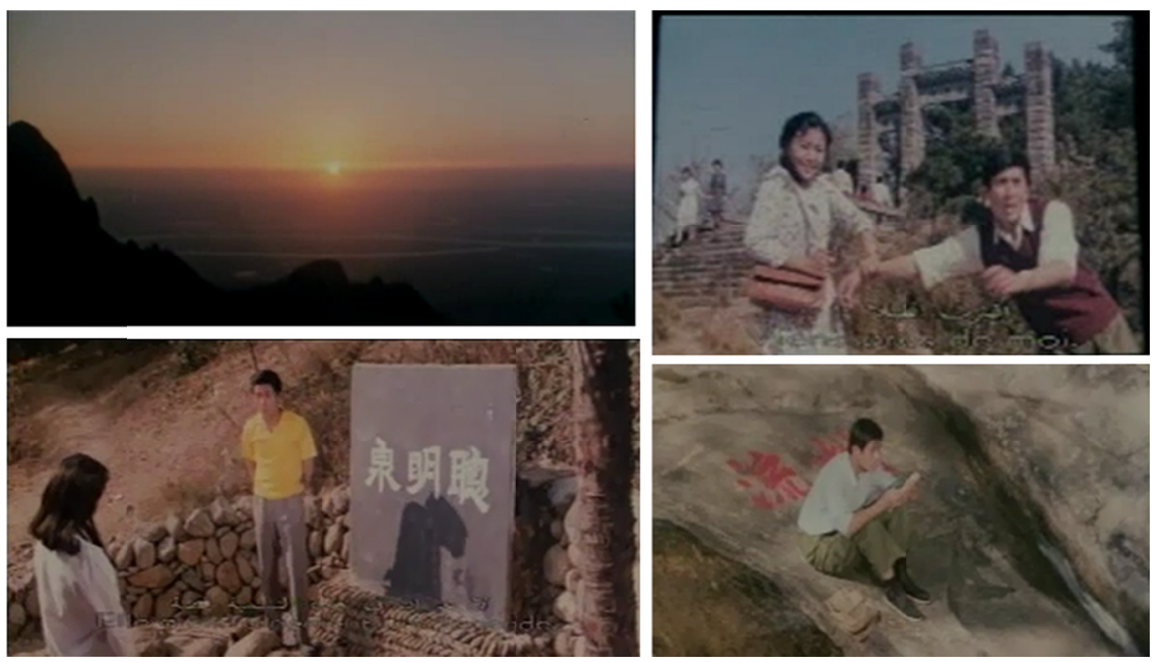

Figure 11. Typical scenes of the movie
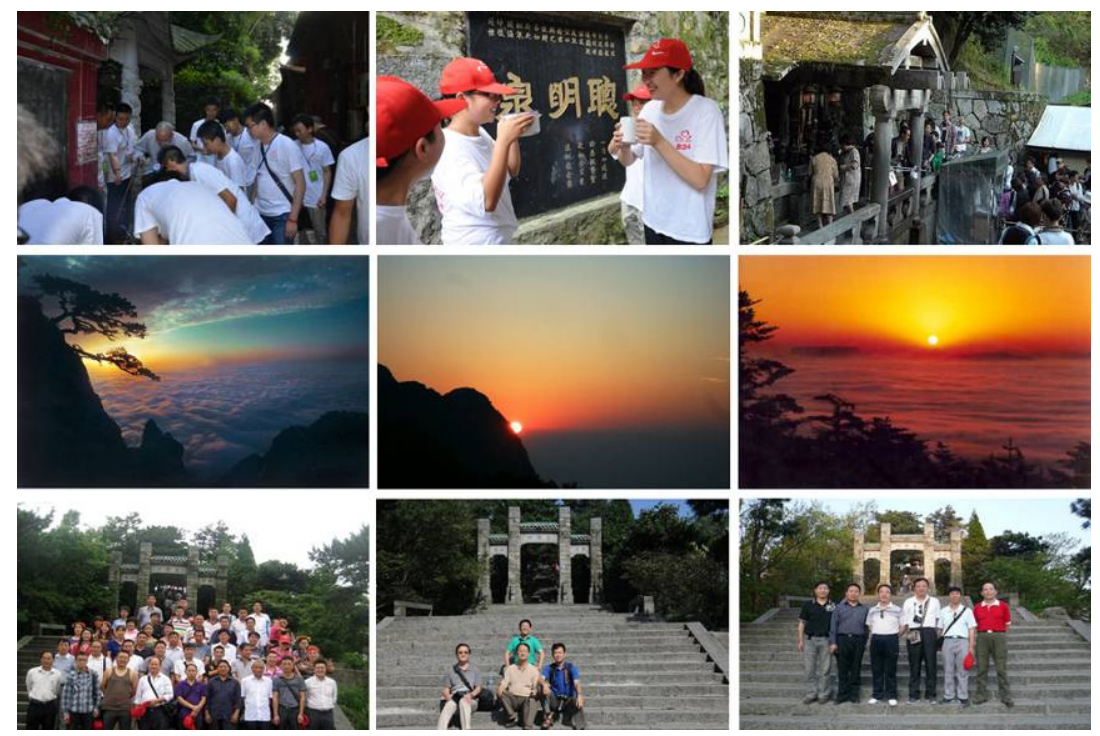

Figure 12. Construction of tourist destinations 
In conclusion, "Romance on Lushan Mountain" (1980) presents the political background of the Chinese mainland in the 1980s and reflects the cultural and ideological transition in such a period through integrated film language containing natural and cultural landscape into storytelling. In the movie, the love story is a product arising out of political factors, but it is still pure and nice, not only showing the desire of individuals, but also highlighting good expectations to motherland's modernization and political peace; as the movie's tourist destination, Lushan is considered as a carrier for constructing ideology, these political and historical events that occurred there and local natural landscape symbolize social environment in China to some extent; as presentation of the scenario in the movie, audiences are deeply impressed by many local attractions, and upgrade their love to local natural landscape of Lushan to the love to China by understanding the travel experience of movie's protagonist, reappearance, subjectivity construction and subjectivity reflection; the movie not only successfully introduced Its main natural scenery, but also enriches Lushan's emotional attribution in "Love" and "patriotism" Therefore, it is not surprising the movie made such a huge impact in the 1980s.

\subsection{Analysis of "Romance on Lushan Mountain 2010"}

Table 4 analyzes the fundamental structure of "Romance on Lushan Mountain 2010". Aesthetic analysis, film editing and sound recording analysis will be discussed with specific scenes of the film.

Table 4. The fundamental structure of "Romance on Lushan Mountain 2010"

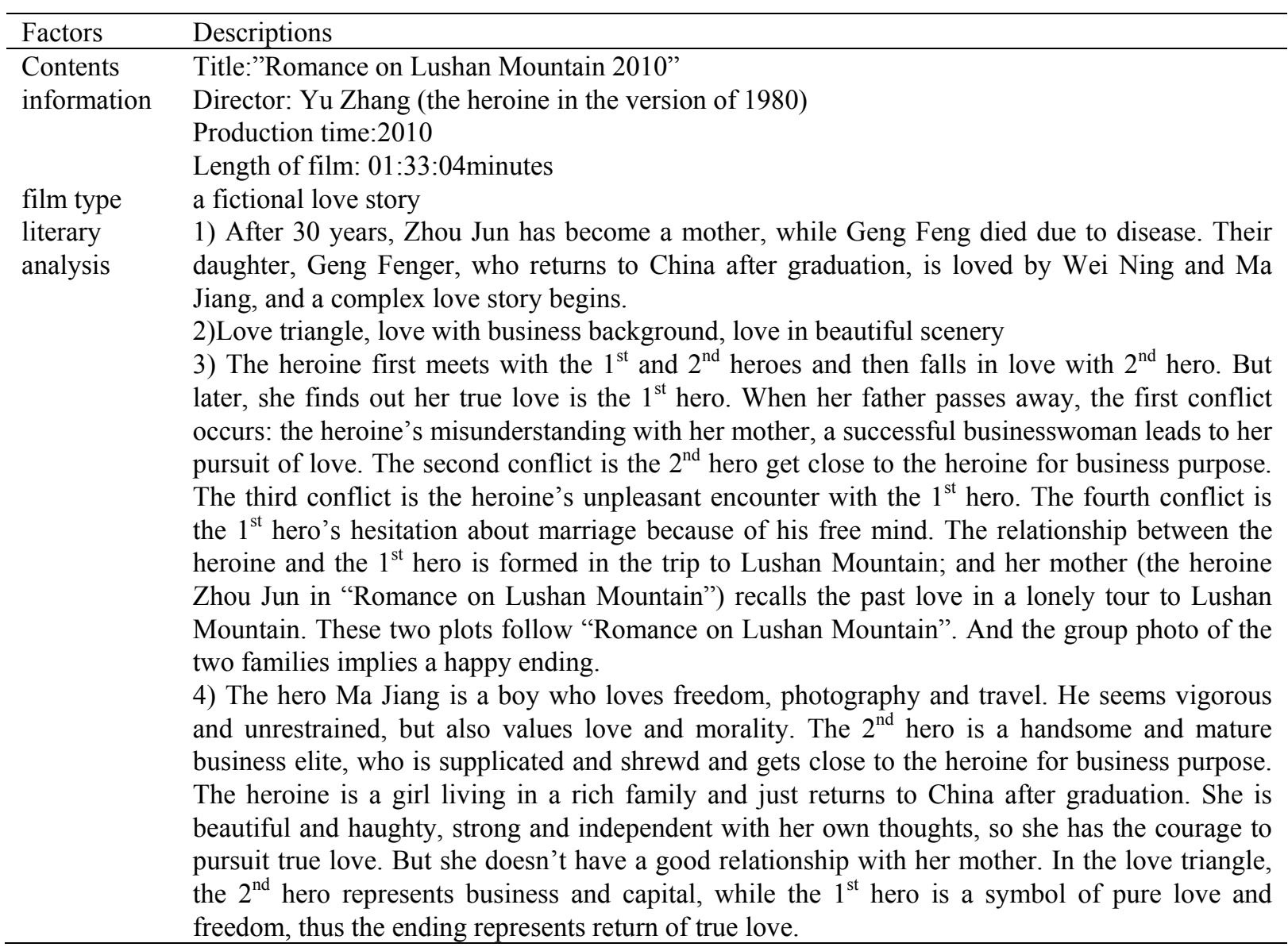

(1) Connection of Scenic Spots between the two films

In "Romance on Lushan Mountain 2010", there is scene that Zhou recalls her meeting with her husband in Flow Stone, their watching the sunrise and their kiss. It is shot from a downward angle, from the distant to the near and with three different facial expressions of Zhou, these three pieces of recalls are connected perfectly (Figure 13). Then a close-up shot of a sketch of Geng intensifies the connection of the two films and reveals Zhou's yearning for her husband (Figure 14). This also shows that even a strong businesswoman has a weak heart and misses her love very much. So her missing towards her husband recalls audience's memory of 1980s. 

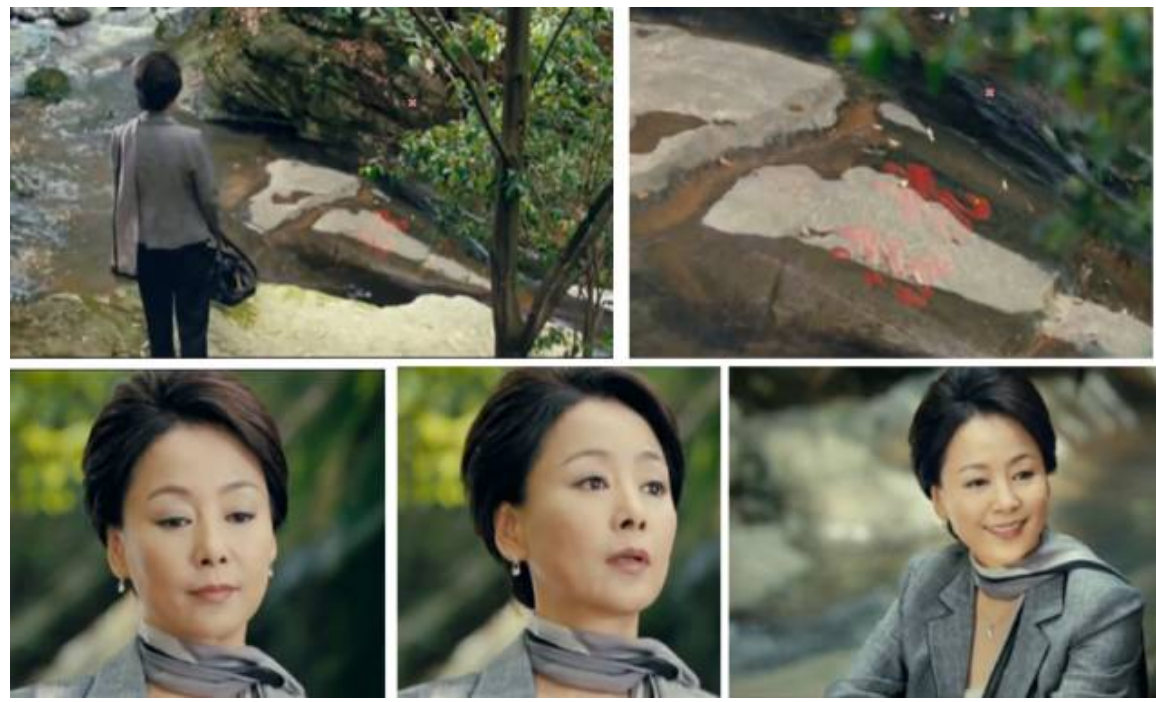

Figure 13. Zhou visits Lushan Mountain Alone
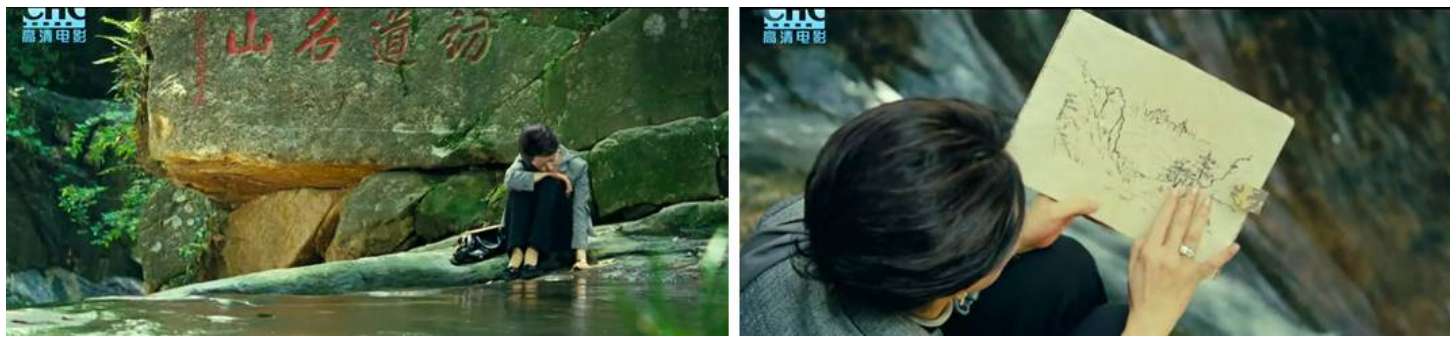

Figure 14. Zhou's missing for Her Husband

The visit of Zhou's daughter, Geng Feier and the hero Ma Jiang to Lushan Mountain together is a turning point that determines their relationship. Geng Feier breaks with Wei Ning and has a cold war with her mother, so she decides to relax herself and pursuits spiritual peace. While Ma Jiang, after lose the job, also comes to Lushan Mountain. They both look for spiritual comfort in a frustrated state; as a result, they find their love for each other in the beautiful scenery. Later, the heroine also rebuilt a harmonious relation with her mother. All natural scenery is presented together with music of bicker, chirping and sound of wind peacefully. And the main screen color is various green that shows the beauty of Lushan Mountain.
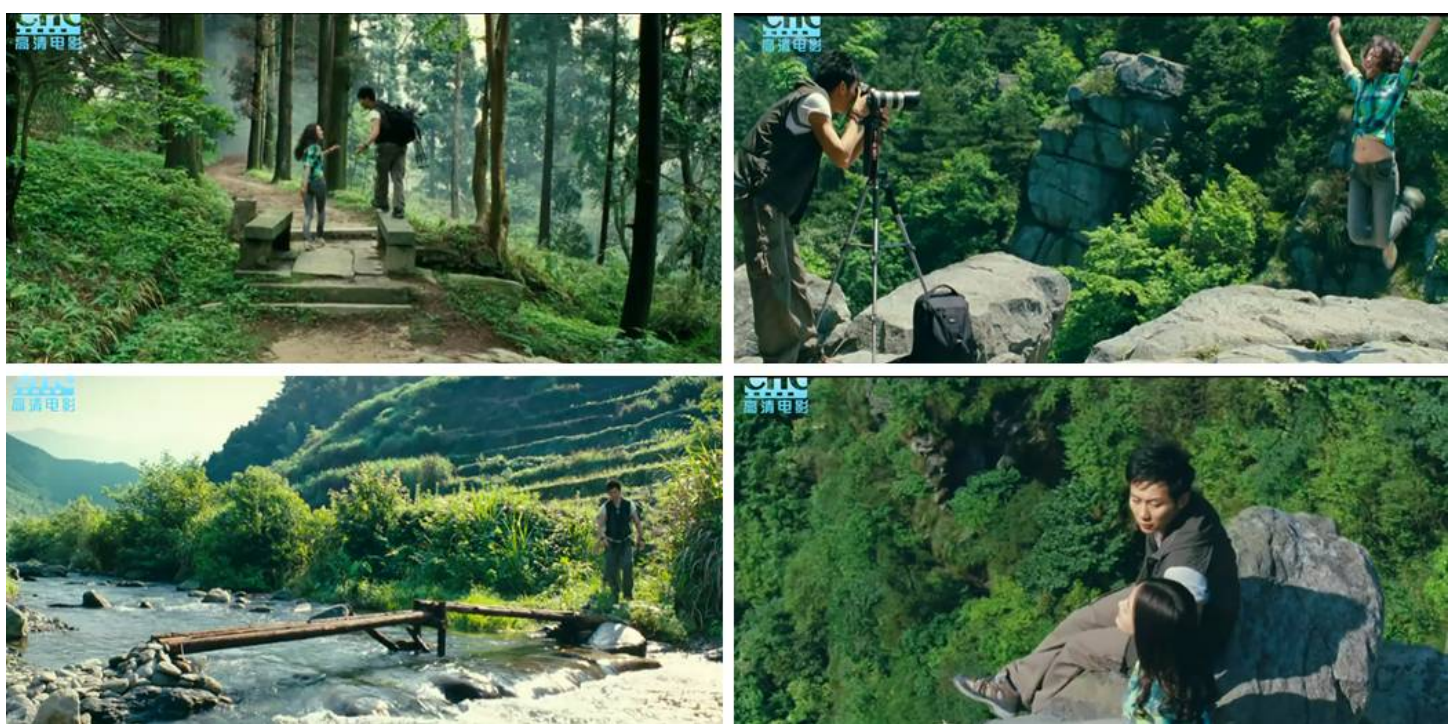

Figure 15. Screenshot of travel of male and female leads in the movie

(2) Development of Lushan Mountain's Scenery

In 7:23 of "Romance on Lushan Mountain 2010", the film gives a panorama of Lushan Mountain from a distant view; the application of modern technology makes it more stereoscopic, brighter and more fantastic. Then the 
film shows an old lane in Lushan Mountain from a downward angle and local people playing Mahjong from a close shot, which aims to show the cultural atmosphere from people's daily life. Remote and soft music is chosen as the background music, along with chirping, makes audience feel rejuvenated

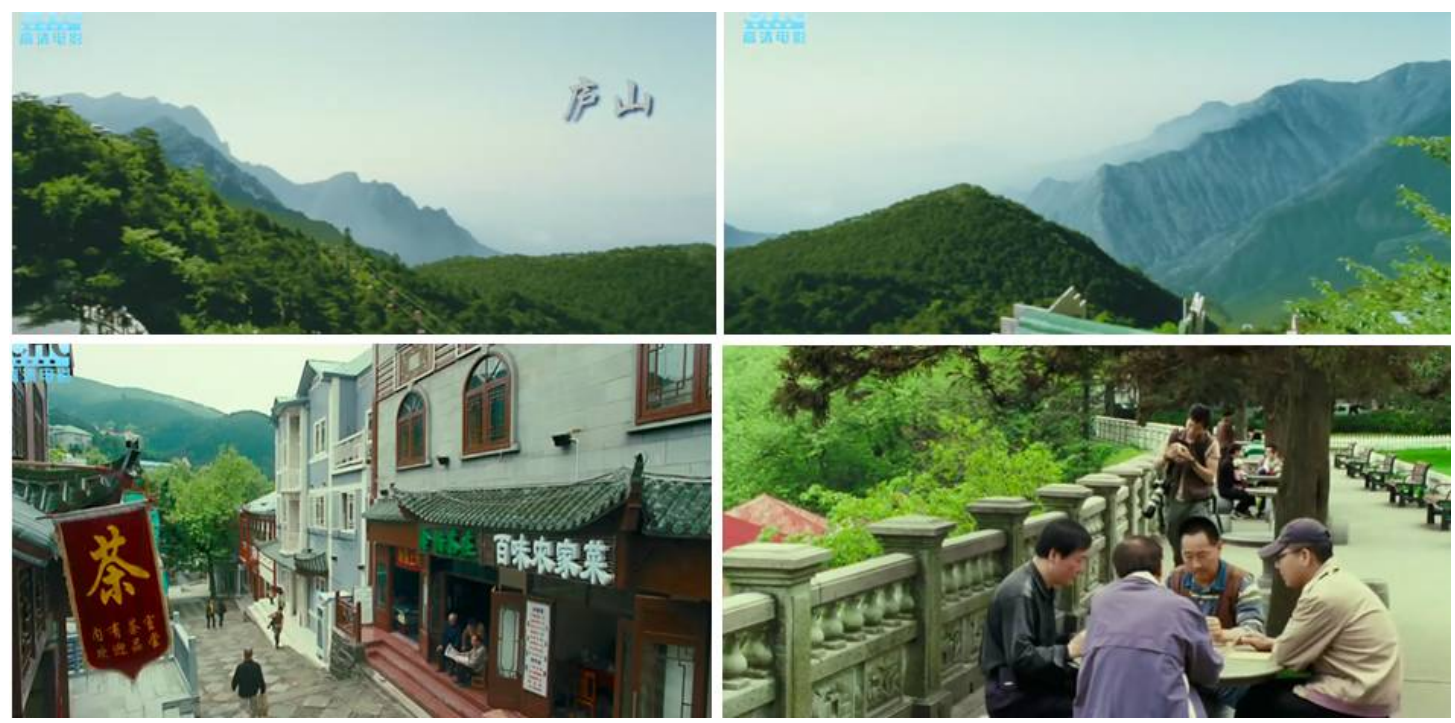

Figure 16. Natural Scenery and Cultural Atmosphere in Lushan Mountain

In "Romance on Lushan Mountain", Zhou lives in Lushan Hotel owned by the government, while in "Romance on Lushan Mountain 2010", a private hotel-Lushan Yuan Villa is owned by Ma Jiang's mother (Figure 17). The existence of the private hotel conforms to the identity of Ma as a photographer and also highlights his difference with businessmen in big cities, which is an implication of the return of pure love. In "Romance on Lushan Mountain 2010", Ma Jiang's mother is a good friend of Zhou, and Ma's mother tells the wildly known love story of Zhou and Geng. This scene can trigger audience's affective commitment to the new film and connect the sentimental value of the two movies. In addition, Ma's mother says that all delicious dishes are made up of potherb, which extends Lushan Mountain as a tourist destination to the popularization of food (Figure 18).
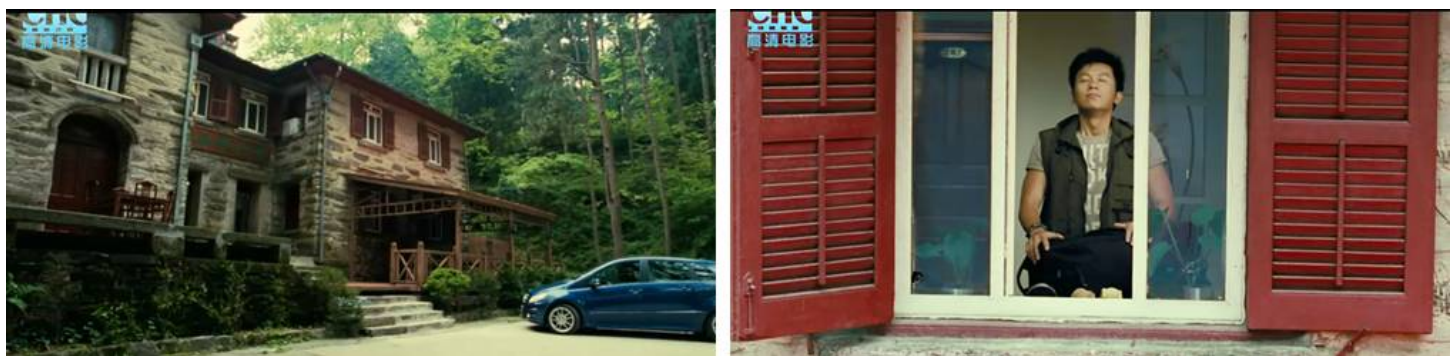

Figure 17. Lushan Yuan Villa
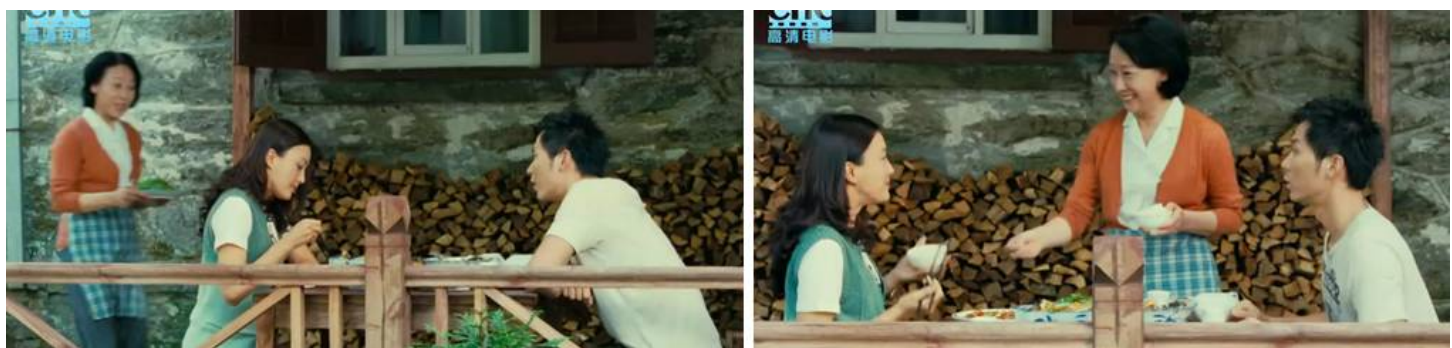

Figure 18. Potherb and Reminisce of Ma's Mother

As shown in figure 19, in "Romance on Lushan Mountain 2010", concert held in the mountain and camping construct a fashionable and vigorous Lushan Mountain. The concert is shot from the distance to the near, from a distant view, full view, close and side view, medium view and close-up view, together with the use of push forward angle, low angle and rotation angle, accompanied by heavy-metal rock ' $n$ ' roll, present a excitement and hilarity. Camping is shot from a downward angle, emphasizing peaceful, broad and cloud-surrounded feeling. And the fresh background music also triggers the imagination of audience, thus brings about the tourist motive besides viewing the natural scenery. This is the construction of fashionable activities in Lushan Mountain. 

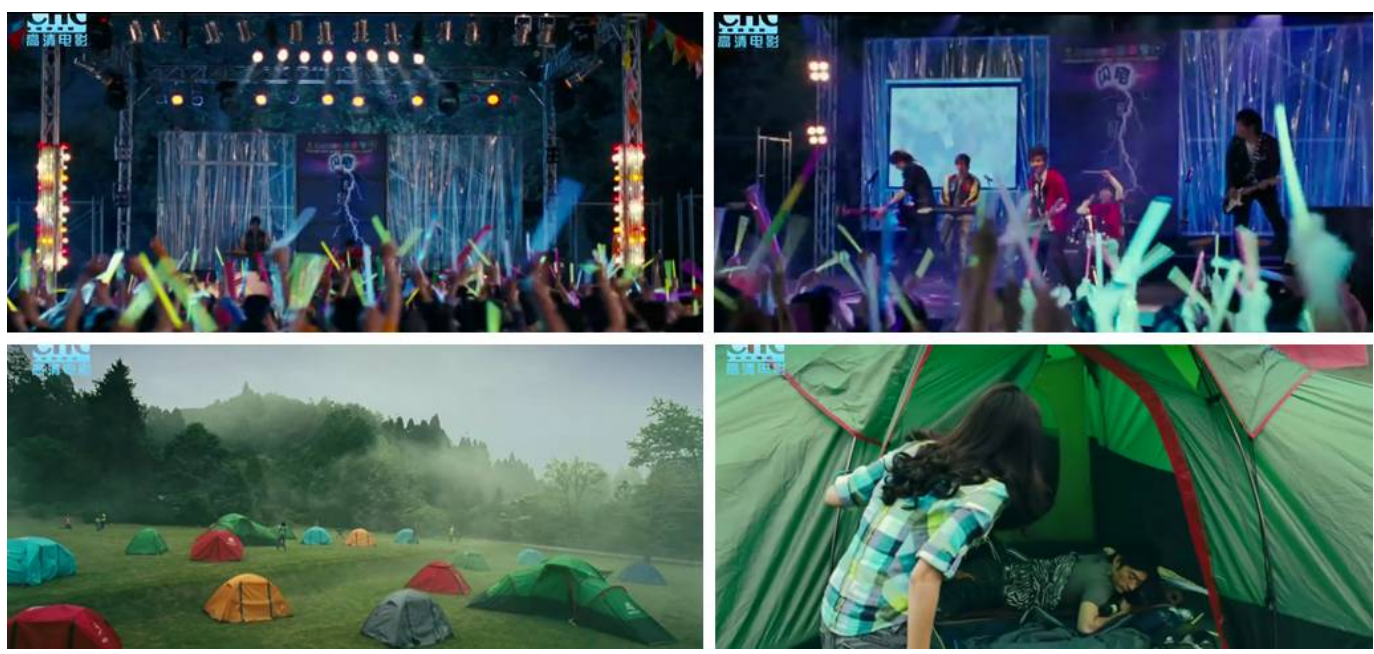

Figure 19. Concert held in the Mountain and Camping

(3) Modern Love in the Background of Metropolis

"Romance on Lushan Mountain 2010" gives a vertical view of Nanjing through a full circle panorama in the beginning. Then flows of the crowds and communication are shown horizontally, which shows a rapid pace of life in Nanjing. Four fast moving shots-from right to left, from down to up, from up to down and from left to right-present high-rise buildings in Nanjing. Finally, the heroine Geng Feier is running in the gym with dynamic background music. All of these lay a foundation for metropolitan, fashionable and rapid atmosphere for the film.

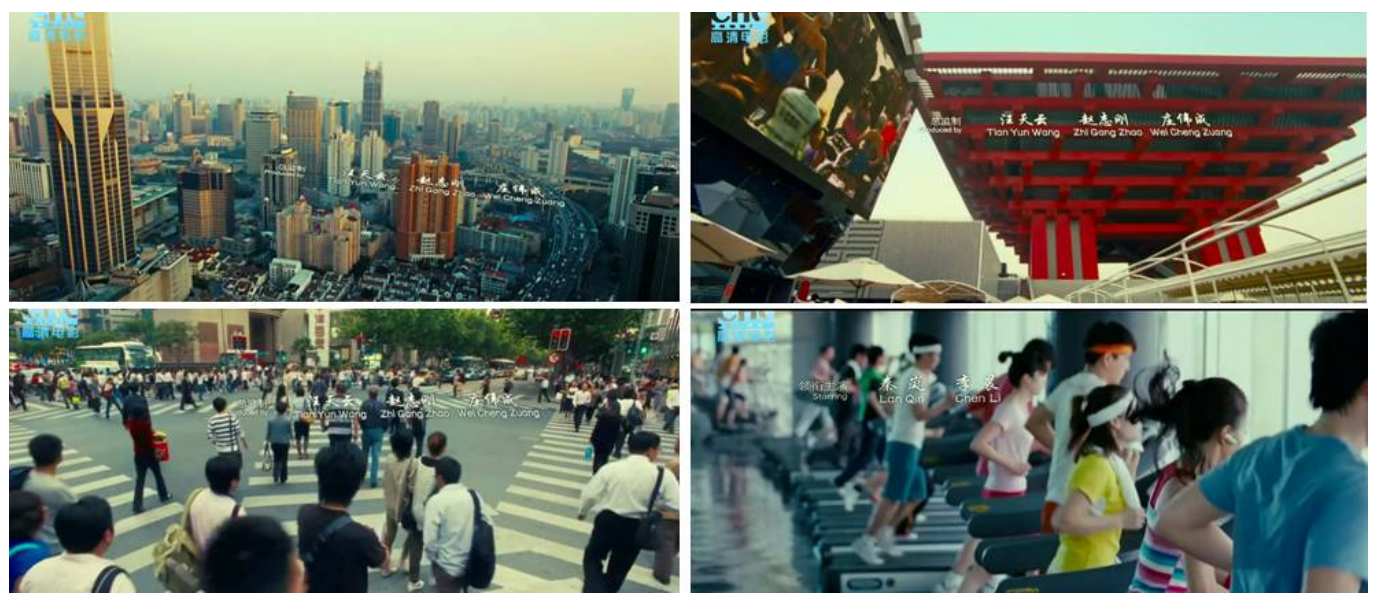

Figure 20. Screenshot in beginning of movie

As for different kinds of activities, the film describes various representative modern activities. Besides the scene in gym mentioned above, bar, yoga, photography, knap sacking and band are all included in this film. In this background, the intricate relationships between different characters are introduced and these activities also come along with characters with different personalities. For example, Zhou, as a successful businesswoman, are associated with yoga, western-style food, red wine and afternoon tea; Geng Feier, a rebellious and fashionable young girl, are associated with fitness, shopping, dinner party and bar; Ma Jiang, a boy who loves freedom, are companied by photography, band and knap sacking.

From the perspective of their love triangle, Wei Ning knows how to take advantage of other people and conditions to get his own success, so he chooses to win the project subject to tender at the expense of love in order to receive recognition of his boss. He pretends to be a soulful, tender, mature and romantic man in front of Geng Feier, so he can easily get response from the heroine at first. But when his business conspiracy is revealed, the plot suddenly changes. So in terms of pure love, he is bound to be a tragic character. As for Ma Jiang, his unpleasant experience with the heroine for the first time is caused by his free and unconstraint characteristics. After the failure of romance relationship, the heroine discovers lost innocence and pure love from Ma Jiang. However, once marriage is involved, a turning point occurs again because Ma hesitates about that. Then he chooses to travel so as to look for the significance of love. Although there are ups and downs in the film, all of 
these are just complex and threadbare. Moreover, excessive commercials and rebel youth intensively stimulate nerves of people in big cities.

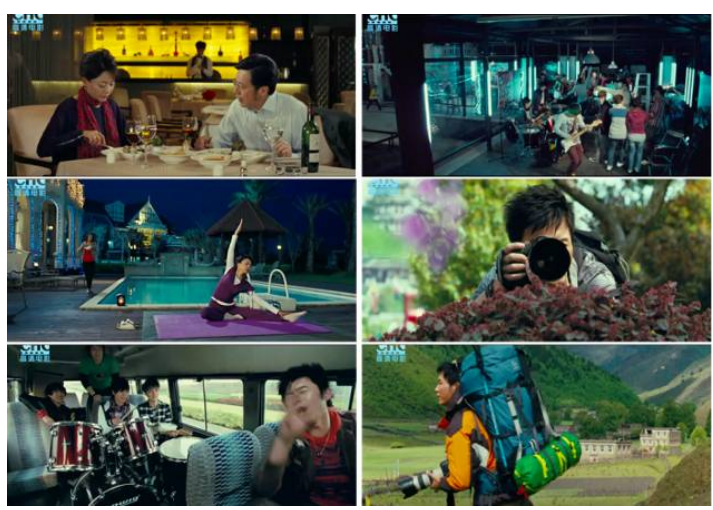

Figure 21. Modern activities

As shown in figure 22, kiss in "Romance on Lushan Mountain" is only presented once, just like a window opened for the return of new enlightenment ideas and a social chapter after the bold and significant revolution. It reveals the change from an old age to a new age and the vigorous passion and pure feelings of young people who suffer from political depression during the Culture Revolution, so it is unforgettable. While in "Romance on Lushan Mountain 2010", kiss not only occurs for just one time, but also is bold and burning. Meanwhile, the film doesn't pave the road sufficiently step by step and it is bold and exaggerated, which cannot resonate in audiences' heart. In one plot, Geng Feier asks the $2^{\text {nd }}$ hero Wei Ning to kiss her in the airport and refuses to go with him because the feeling is not right. At this time, the $1^{\text {st }}$ hero Ma Jiang suddenly appears, and they hug and kiss each other. This plot doesn't conform to the common sense. And it is too conventional to set such a plot that Ma rushes to the airport for the heroine. From this aspect, "Romance on Lushan Mountain 2010" has too many kisses to explain the meaning of pure love.
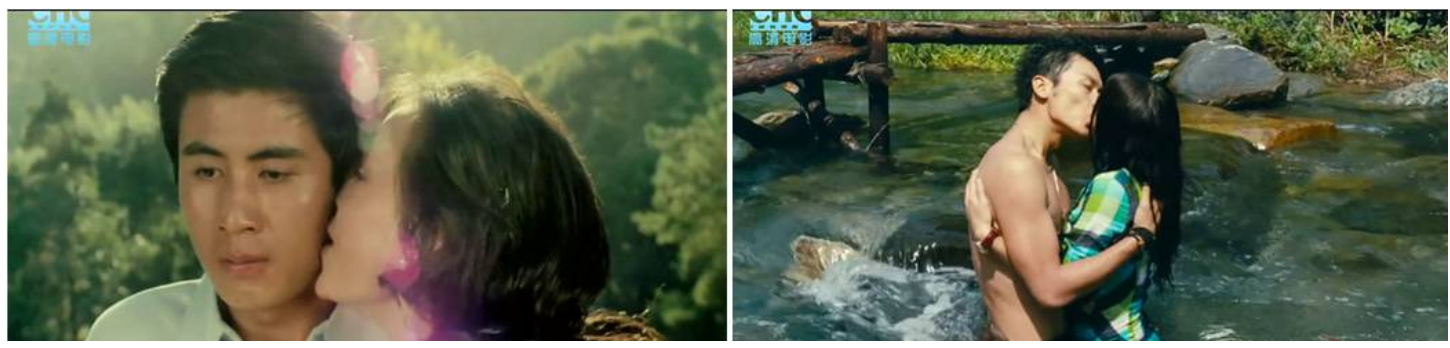

Figure 22. Comparison on "Kiss" scenarios in two versions

(4) Influence of excessive commercialization on tourism destinations

"Romance on Lushan Mountain 2010" spends about 20 minutes on presentation of destination image, and another 20 minutes on showing Nanjing (as shown in Table 5); the authors collected related information and found that before the movie is shot, Nanjing obtained the qualification of organizer "The Youth Olympic Games 2014" successfully, and thus local administrators hoped to enhance their city brand and establish their own urban image ASAP; invested hugely in production of "Romance on Lushan Mountain 2010"; local administrators hoped to develop the movie into a brand image campaign for "New Nanjing", and could create huge influence like previous version of "Romance on Lushan Mountain". However, this new movie confuses the audiences and omits Nanjing's urban features, such as long-standing history and rich cultural deposit, because it contains more than one destination. Therefore, from this point of view, excessive commercialization is a failure in the new version.

In conclusion, "Romance on Lushan Mountain 2010" starts scenario under modern urban background, and tells a complex story; By Zhou's recalling to attractions of Lushan, it is effectively linked and matched with 1980 version, strengthens connection between two versions. When hero and heroine visit to Lushan again, the heroine finds her true love, and reconciles with his mother, thus highlighting "true love" elements implied by Lushan. Regarding construction of tourist destinations, the movie shows simple natural scenery, also integrates other various modern elements to enrich the image better. However, because it contains more than one destination and is commercialized redundantly, the theme "true love" contained in the movie isn't upgrade to a spiritual and emotional resonance among audiences. 
Table 5. Nanjing scenic spots summary in "Romance on Lushan Mountain 2010"

\begin{tabular}{|c|c|}
\hline Scenic spots & Features \\
\hline Stone City Park & It consists of Spring Dawn, Snow in Stone City and Autumn Night in the Mountain. \\
\hline $\begin{array}{l}\text { Ming Dynasty } \\
\text { City Wall }\end{array}$ & $\begin{array}{l}\text { It was built after Zhu Yuanzhang intruded into Nanjing and costed } 20 \text { years to finish. And it is } \\
\text { the largest city wall in Nanjing. }\end{array}$ \\
\hline $\begin{array}{l}\text { Historic Site of } \\
\text { Treasure Ship }\end{array}$ & $\begin{array}{l}\text { It is located in the historic site of Longjiang Treasure Ship Factory opened in } 600 \text { years ago } \\
\text { and is built for } 600 \text { anniversary of Zhenghe's travelling to the west. }\end{array}$ \\
\hline $\begin{array}{l}\text { Yun Jing } \\
\text { Museum }\end{array}$ & Chinese national brocade art, especial Nanjing brocade is exhibited here. \\
\hline Yi He Road & $\begin{array}{l}\text { No traffic and no stores during } 70 \text { years after construction enable a quiet housing environment } \\
\text { in this region. }\end{array}$ \\
\hline $\begin{array}{l}\text { Sun Yat-sen } \\
\text { Mausoleum }\end{array}$ & $\begin{array}{l}\text { It has the mausoleum and monument of Sun Zhongshan who is a great politician and } \\
\text { revolutionist in modern China. The main buildings include memorial archway, tomb passage, } \\
\text { the door of mausoleum the pavilion with a tablet the sacrifice hall and coffin chamber. }\end{array}$ \\
\hline Lion Bridge & It is full of restaurants selling Nanjing snacks and has the famous Lion Pavilion. \\
\hline
\end{tabular}

\section{Discussion}

In 1980, a new era appeared in China after reform and opening up policy was implemented; at that time, China's moviegoers reached 29.2 billion person-times; regardless of in urban or rural regions, cinemas and outdoor movie sites had become the most important social places (Junru Huang, 2010). After CCR, due to changes in social environment and major social values, people changed their aesthetic appeal to movies. "Romance on Lushan Mountain" (1980) made great impact on the aesthetics, nature and values of model operas established in CCR. From the view of aesthetics today, its artistic value is not outstanding, but it is worth noting that the movie has a nature of "political melodrama" (Jie Yang, 2012; Guoli Dong, 2013). The movie takes love story of hero and heroine as the main line, highlights the theme of unity and reunification of the motherland, also reflects consistence between development trend of young generation and the country's future and destiny.

The movie aims at presenting a magnificent artistic conception, but not stereotyped, not only showing the beautiful scenery of Lushan, praising magnificent rivers and mountains of the motherland, also bringing out the great psychological world of characters herein, and glorifying their true love. Thereby, the movie, indeed, integrates the natural scenery, personal passions and national politic future closely as a whole, and it is considered as a cultural product under "socialist education and entertainment integrated" purpose and basing on the needs for country's political orientation. In the movie, both actor and actress made several visits to Lushan, and such the visits help travelers contact, record and interpret natural elements, various attractions provide an opportunity for further showing personal emotion or adventure experience. Change in spatial location creates a dramatic atmosphere; several classic scenes in the movie inspire the imagination and expectations of tourists, resulting in a long-lasting and extensive conduction of image and emotion; however, under the political background in 1980s, such this destination image is more single.

By contrast, "Romance on Lushan Mountain 2010", which was produced after three decades, attaches more attentions to modern cities, skyscrapers and love of modern men and women. Without any political impression, it is capable to adhere to the styles of the previous version. Firstly, it inherits the role of previous version in 1980: to lead fashion and trend in an era, as a pioneer-style work in emotion and styling; as same as 1980 version, it contains many contemporary lifestyles of young people such as gym, outdoor forest music festival, travel photographer, bars, western food parties and others; secondly, "Romance on Lushan Mountain 2010" still adheres to some the essences of love as shown in previous version such as "No matter how era changes, true love has never gone away", although it is hugely influenced by modern ideas. From the perspective of spreading and communication, 2010 version omits introduction of attractions and re-visit. It sets up emotional connection between two movies through memories to evoke the audiences' resonation. By showing travel process by hero and heroine, Lushan beauty is expressed and enriched in a three-dimensional manner, though modern photographic techniques, thus to inspire the audiences' yearning for Lushan; Moreover, the movie also integrates different types of elements such as cultural atmosphere, local conditions and customs, camping, mountain concerts, etc, and enriches image of tourist destination, and keeps pace with current era. However, the inadequacy of the movie is commercial propaganda and introduction to other attractions except for Lushan, thus to confuse current tourists' image to Lushan. 
Till now, the past thirty years have passed away since "Romance on Lushan Mountain" (1980) was released. Due to change in historical background, the movie's love background is changed from political background to commercial background. Today, people's living habits and tourisms are more diversified, in addition to the beautiful scenery; Lushan is enriched with more fashion content. Therefore, to recompose and continue a movie is not an easy work, especially for a movie with wide influence; but as said before, "No matter how era changes, true love has never gone away," a kissing scenario has lasted its influence for three decades, two versions of "Romance on Lushan Mountain" bring us not only charm of Lushan, and also expectations for beautiful love.

\section{Reference}

Andrew, L. (2011). Image and perceived risk: A study of Uganda and its official tourism website. Tourism Management, 32, 78-97. http://www.sciencedirect.com/science/article/pii/S0261517710001081

Boraas, A. (2000). Guide to writing an analytic film review. Retrieved from http://chinook.kpc.alaska.edu/ anthro/anthropotogy/analyzingfilm.htm

Brown, D. (2001). Some cursory notes on "reading” a film. Retrieved from http://www.english.upenn.edu/Grad/ Teachweb/dbfilm.heml

Beeton, S. (2005). Film-induced tourism. Clevedon: Channel View Publications.

Busby, G., \& Klug, J. (2001). Movie-induced tourism: The challenge of measurement and other issues. Journal of Vacation Marking, 7(4), 316-332.

Baloglu, S. (2001). Tourism destination images of Turkey, Egypt, Greece, and Italy as perceived by US-based tour operators and travel agents. Tourism Management, 22, 32-51. http://www.sciencedirect.com/science/ article/pii/S0261517700000303

Castelltort, M., \& Mader, G. (2010).Press media coverage effects on destinations: Amonetary public value (MPV) analysis. Tourism Management, 17, 407-418. http://www.sciencedirect.com/science/article/pii/S0261517 709001186

Cohen, E. (1989). The Tourist Guide: The Origins, Structure and Dynamics of a Role. Annals of Tourism Research, 6(1), 49-65. http://www.sciencedirect.com/science/article/pii/0160738385900374

Connell, J. (2005). 'What's the story in Balamory?': The impacts of a children's TV program on small tourism enterprises on the Isle of Mull, Scotland. Journal of Sustainable Tourism, 13, 228-255.

Connell, J. (2009). Balamory revisited: An evaluation of the screen tourism destination-tourist nexus. Tourism Management, 30, 194-207. http://www.sciencedirect.com/science/article/pii/S026151770800099X

Chalfen, R. M. (1979). Photography's role in tourism: Some unexplored relationships. Annals of Tourism Research, 6(4), 435-447. http://www.sciencedirect.com/science/article/pii/0160738379900069

Liu, D., \& Bao, J. (2006). Desire to peep, image memory and self-identity: The tourists photography behavior research in Western academic world. Tourism Tribune, 4, 88-93.

Edwards, E. (1996). Postcards—greetings from another world. The Tourism Image, Myths and Myth Making in Tourism. Wiley, Chichester, UK.

Echtner, C. M. (2002), The content of Third World marketing: A 4A approach. The International Journal of Tourism Research, 13(6), 223-241. http://www.sciencedirect.com/science/article/pii/S0160738303001488

Escher, A., \& Zimmerman, S. (2001). Geography meets Hollywood: The role of landscape in feature films. Geographische Zeitschrift, 89, 227-236

Gundle, S. (2002). Hollywood glamour and mass consumption in postwar Italy. Journal of Cold War Studies, 4(3), 95-118.

Greertz, C. (1973). The interpretation of cultures. Basic Books, New York.

Guoli Dong. (2013). The nation-state imagination of the 1980s. Sociology and social work, 9, 1-9.

Hunter, W. C. (2008). A typology of photographic representations for tourism: Depictions of groomed spaces. Tourism Management, 29, 69-82. http://www.sciencedirect.com/science/article/pii/S026151770700060X

Hunter, W. C. (2013). China's Chairman Mao: A visual analysis of Hunan Province online destination image. Tourism Management, 34, 124-146. http://www.sciencedirect.com/science/article/pii/S0261517712000623

Huang, J. (2010). Looked from the "Romance on Lushan Mountain" of the mass of film aesthetics in the eighty's. The Southern Forum, 3, 97-99. 
Yang, J. (2012). The change of contemporary Chinese culture from "Romance on Lushan Mountain" (1980) to "Romance on Lushan Mountain 2010". Youth Literator, 2, 246-247.

Bai, K. (2008) Research on connection of symbol metaphor of tourism destination image: Taking Shanxi province, China, as an example. Resource Science, 8, 1184-1190.

Kim, S. (2012). Audience involvement and film tourism experiences: Emotional places, emotional experiences. Tourism Management, 33, 376-387. http://www.sciencedirect.com/science/article/pii/S0261517711001026

Xiao, L. (2009). Taiwan tourism destination image via the spread of the Internet: The content analysis based on cross-strait related websites. Tourism Tribune, 3, 75-81.

Liu, L. (2013). Tourism destination image perception and tourists travel intentions: Comprehensive study based on the perspective of film and TV tourism. Tourism Tribune, 9, 61-72.

Lin, Y. S., \& Huang, J. Y. (2006). Internet blogs as a tourism marketing medium: A case study. Journal of Business Research, 59, 32-49.

Markwick, M. (2001). Postcards from Malta: Image, consumption, context. Annals of Tourism Research, 28(2), 417-438. http://www.sciencedirect.com/science/article/pii/S0160738300000499

Markwell, K. W. (1997). Dimensions of photography in a nature-based tour. Annals of Tourism Research, 24(1), 131-155. http://www.sciencedirect.com/science/article/pii/S0160738396000539

Monaco, J. (2000). How to read a film: Movies, Media, Multimedia. Oxford University Press, London.

Offler, N, (1999). Shock, judgment, and the stereotype: Exploring the role of emotional response in ethnographic film reception. Retrieved from: http://cc.joensuu.fi/naomi.htm

Pritchard, A. (2001). Tourism and representation: A scale for measuring gendered portrayals. Leisure Studies, 20, 79-94.

Rose, G. (2001). Visual Methodologies. Sage, London.

Reiter, R., \& Mackworth, A. (1989). A logical framework for depiction and image interpretation. Artificial Intelligence, 41, 125-155.

Stepchenkova, S., \& Fangzi Zhan. (2013). Visual destination images of Peru: Comparative content analysis of DMO and user-generated photography. Tourism Management, 36, 44-68. http://www.sciencedirect.com/ science/article/pii/S0261517712001422

Stepchenkova, S. (2006). The destination image of Russia: From the online induced perspective. Tourism Management, 27, 64-83. http://www.sciencedirect.com/science/article/pii/S0261517705001536

Salazar, N. (2012). Tourism imaginaries: A conceptual approach. Annals of Tourism Research, 39(2), 863-882. http:/www.sciencedirect.com/science/article/pii/S0160738311001642

Wang, T. (2012). The content analysis of tourism virtual community share (Master's thesis, Jiangxi normal University, Jiangxi China).

Tzanelli, R. (2003). Casting the neohellenic "Other": Tourism, the culture industry, and contemporary orientalism in Captain Corelli's Mandolin. Journal of Consumer Culture, 3(2), 217-244.

Uzzell, D. (1984). An alternative structuralist approach to the psychology of tourism marketing. Annals of Tourism Research, 11(1), 79-99. http://www.sciencedirect.com/science/article/pii/0160738384900975

Zhang, W. (2010). Regional tourist destination brand building based on analysis of symbol communication. Tourism Tribune, 4, 53-57.

Winler, T. (2003). Angkor meets Tomb Raider: Setting the scene. International Journal of Heritage Studies, 8(4), 323-336.

Hao, X., \& Ryan, C. (2013). Interpretation, film language and tourist destinations: A case study of Hibiscus Town, China. Annals of Tourism Research, 42(1), 334-358. http://www.sciencedirect.com/science/article/ pii/S0160738313000388

\section{Copyrights}

Copyright for this article is retained by the author(s), with first publication rights granted to the journal.

This is an open-access article distributed under the terms and conditions of the Creative Commons Attribution license (http://creativecommons.org/licenses/by/3.0/). 